\title{
Interprofessional Experience for Future Education Professionals: School Psychology and Speech-Language Pathology Students
}

\author{
Shari L. DeVeney \\ University of Nebraska at Omaha, sdeveney@unomaha.edu \\ Brian McKevitt \\ University of Nebraska at Omaha, bmckevitt@unomaha.edu \\ DOI: https://doi.org/10.30707/TLCSD5.1.1624982519.476871
}

Follow this and additional works at: https://ir.library.illinoisstate.edu/tlcsd

Part of the Higher Education Commons, School Psychology Commons, and the Speech Pathology and Audiology Commons

\section{Recommended Citation}

DeVeney, Shari L. and McKevitt, Brian (2021) "Interprofessional Experience for Future Education Professionals: School Psychology and Speech-Language Pathology Students," Teaching and Learning in Communication Sciences \& Disorders: Vol. 5: Iss. 1, Article 1. DOI: https://doi.org/10.30707/TLCSD5.1.1624982519.476871

Available at: https://ir.library.illinoisstate.edu/tlcsd/vol5/iss1/1

This Scholarship of Teaching and Learning Research is brought to you for free and open access by ISU ReD: Research and eData. It has been accepted for inclusion in Teaching and Learning in Communication Sciences \& Disorders by an authorized editor of ISU ReD: Research and eData. For more information, please contact ISUReD@ilstu.edu. 


\title{
Interprofessional Experience for Future Education Professionals: School Psychology and Speech-Language Pathology Students
}

\author{
Abstract \\ Educational training programs are tasked with addressing potential barriers to interprofessional practice \\ through experiences that promote interprofessional collaborations. The present study of interprofessional \\ experiences (IPE) had both research and pedagogical purposes. The research purpose was to describe \\ graduate student self-perceptions related to interprofessional teaming/collaboration before and after an \\ IPE involving two educational training programs, school psychology and speech-language pathology. The \\ pedagogical purpose was to convey a detailed description of a case-based IPE offered as a course \\ assignment and offer implementation suggestions. Participants in this course-based IPE were 109 \\ students in the school psychology and speech-language pathology graduate programs at a medium-sized \\ midwestern university over a four-year period. Students in both programs engaged in the IPE as part of a \\ graded class assignment involving case studies. Pre- and post-IPE surveys were used to determine \\ changes in students' perceptions of their own profession and training, others' professions, and \\ collaboration and teaming. Results indicated that the perception of students from both programs \\ significantly improved following the IPE. Improved perceptions of collaboration, teaming, and one \\ another's professions were sustained over four years of implementation. Implications for research, \\ practice, and training are discussed.

\section{Keywords} \\ interprofessional experience, school psychology, speech-language pathology, graduate students

\section{Cover Page Footnote} \\ The authors would like to thank and acknowledge the student cohorts who participated in our graduate \\ courses over the years and helped in refining the IPE assignment referenced in this article through their \\ feedback and suggestions.
}


Many training programs, including those for speech-language pathologists and school psychologists, note the importance of interprofessional education (IPE) to promote interprofessional communication and further the development of interprofessional practices (IPP) in the workplace. The World Health Organization (WHO; 2010) detailed the importance of collaborative practices for improving global health and educational systems. The WHO enacted specific guidelines for training and practice associated with IPE (2010). These guidelines help to foster collaborative relationships across professions for the benefit of continuity and quality service provision (WHO, 2010). The WHO also defined key terminology associated with IPE training and described the rationale for how this educational training emphasis on collaboration fosters IPP to the benefit of patients, students, and their caregivers (WHO, 2010). According to the WHO (2010), health and education systems around the world are fragmented and not meeting the needs of those being served within these systems. There is a need to foster collaborative-ready practitioners prepared to address complexity and change in the face of increasing complex workplace issues including changes to traditional professional roles. To that end, the WHO (2010) defined key terminology such as IPE, which "occurs when two or more professions learn about, from and with each other to enable effective collaboration and improve health outcomes" (p. 13) and provided a framework for its inclusion in educational training programs. Members of the WHO rationalized that once students understand how to work interprofessionally through effective training experiences, they will be prepared to engage in IPP to the benefit of those they serve.

To align student engagement in IPE with future IPP benefits, four core competencies were outlined by the Interprofessional Education Collaborative (IPEC) in 2016. These included: competencies involving values and ethics, roles and responsibilities, interprofessional communication, and teams and teamwork (IPEC, 2016). In essence, the core competencies encourage working with individuals in other professions to (1) promote a climate of trust, respect, and shared values, (2) demonstrate an understanding of differing roles and responsibilities and use this knowledge to advance patient/client care, (3) communicate appropriately with clients and their caregivers about prevention, assessment, and treatment issues, and (4) foster a team approach for planning, implementing, and evaluating programs and policies affecting client care (IPEC, 2016). Training program IPE experiences can be designed to address any or all of the competencies outlined.

\section{IPE Implementation in Training Programs}

Following the WHO initiative and the subsequent outlining of the IPEC core competencies, many documented the inclusion of IPE in discipline-specific health-science training programs (e.g., Center for Interprofessional Education, University of Toronto, n.d.; IPEC, 2016; Thistlethwaite, 2016). Others documented the need for IPE specifically in the training of special education professionals (Dessent, 1996; Johnson, 2016). Further, IPE is now included in the current standards and guidelines for discipline-specific training programs in special education systems, such as those of school psychology (National Association of School Psychologists [NASP], 2010) and speechlanguage pathology (American Speech-Language-Hearing Association [ASHA], n.d.; Council on Academic Accreditation in Audiology and Speech-Language Pathology, 2019). For professionals working in special education, not only are collaborative practices encouraged in training programs, they are also required by U.S. federal law in the form of interdisciplinary teams: Coordinated

groups of professionals from differing disciplines working collaboratively together for 
administration of special education services (Individuals with Disabilities Education Act [IDEA], 2004).

Several small-scale studies demonstrated the effective use of IPE as part of comprehensive discipline-specific training programs to promote the development of collaborative-ready practitioners. For example, in a survey study, 61 undergraduate preprofessional health science students identified the effects of team-based decisions within a patient-centered health care approach through participation in IPE (Neville et al., 2013). At the graduate level, students expressed positive outcomes from health care IPE opportunities. Small groups of graduate student participants in IPE reported their feelings of competence increased (Coiro et al., 2016) and reportedly maintained those positive feelings for at least one year after the experience (Wallace, 2017). Ludwig and Kerns (2019) and Pfeiffer, Pavelko, and Ingram (2018) noted the IPE framework is applicable also to training programs for education-related disciplines. To that end, IPE opportunities targeting future special education professionals have been developed and piloted with positive student participant outcomes noted (Hong \& Shaffer, 2015; Miolo \& DeVore, 2016). Unfortunately, large-scale research on the effectiveness of IPE in education-related disciplines still remains absent from the empirical literature.

\section{Student Exposure to IPE and Practitioner Engagement in IPP}

Research and standards for training guidelines indicate IPE can be an effective and integral educational tool, yet many students have not had exposure to it. Swain, McKevitt, and Ritzman (2016) surveyed over 70 graduate students enrolled in special education-related training programs including special education, school psychology, and speech-language pathology. They found many of the students had experiences collaborating with other within-discipline peers, yet significantly fewer had collaborative experiences with students outside their discipline (Swain et al., 2016). Those who did have experience with IPE reported it as a positive educational experience with application to their future work as special education service providers (Swain et al., 2016). Although this study took place at only one university, its results are largely generalizable. Palikara, Lindsay, Cullen and Dockrell (2007) surveyed 51 practicing school psychologists and 120 speechlanguage pathologists who responded similarly to the students in the study by Swain and colleagues (2016). Palikara and colleagues (2007) found the professionals reported a positive regard for collaborative practices, but there was little evidence they regularly engaged in IPP in their role as special education service providers. This paradox of positive regard for IPP with lack of implementation was also noted by Coiro and colleagues (2016).

Special education professionals, including school psychologists and speech-language pathologists, would ideally engage in IPP for a variety of reasons (e.g., enhanced understanding of disciplinespecific roles and responsibilities, increased interprofessional communication, more efficient use of a teamwork approach to service delivery). For these professions, engagement in routine IPP is even associated with greater job satisfaction (Ocampo \& Kennedy, 2019). Unfortunately, optimal, routine engagement in IPP may not be the reality for school-based special education professionals. Pfeiffer, Pavelko, Hahs-Vaughn, and Dudding (2019) surveyed 474 practicing school-based SLPs and found that very few engaged in IPP during initial student evaluations (8\%) and intervention sessions (14\%); however, more were likely to engage in IPP during eligibility meetings (43\%). 
The national sample of SLPs surveyed in this study identified several barriers to the functional use of collaborative practices in school settings, including time and scheduling constraints, resistance from other professionals, lack of employer/administrator support, and lack of access to collaborative team training (Pfieffer et al., 2019). Additional barriers included professional differences in views on the purpose and use of cognitive assessments and information sharing (Dunsmuir et al., 2006). Collaboration barriers also include entrenched interprofessional stereotypes and an unwillingness to "concede superiority" to professional groups deemed comparatively less competent or valuable than others (Barnes et al., 2000, p. 577). Effective IPP may also be hindered by differences in workplace priorities and student service provision preferences (Palikara et al., 2007).

Training programs are tasked with addressing these potential barriers to IPP through educational experiences that promote interprofessional collaborations as a means to stimulate teamwork practices for future practitioners. Some programs addressed collaborative barriers through simulated teamwork experiences (Towson et al., 2018) and others used IPE (DiVall et al., 2014; Dobbs-Oats \& Watcher Morris, 2016; Hong \& Shaffer, 2015; Miolo \& DeVore, 2016; Neville et al., 2013; Pechak et al., 2013; Wallace, 2017; Zhao et al., 2015). The present study focused on IPE because IPE has a greater body of evidence than simulation experiences, indicating the potential to proactively address collaboration barriers.

\section{Current Study}

The current study had both research and pedagogical purposes. The research purpose was to describe graduate student self-perceptions related to interprofessional teaming/collaboration before and after an IPE experience involving two professional training programs, school psychology and speech-language pathology. This portion of the study used survey methodology to address questions of interest. The pedagogical purpose was to convey a detailed description of a case-based interprofessional experience offered as a course assignment that may be replicated by others. This portion of the study contained narrative information related to the experiences of the authors while implementing the IPE experience.

Previous research analyzed students' perceptions of teaming and collaboration, but most described brief or one-time experiences (Coiro et al., 2016; DiVall et al., 2014; Neville et al., 2013; Pechak et al., 2013; van Soeren et al., 2011; Wallace et al., 2002). To expand on previous research, the current study provides cross-sectional data from multiple student cohorts regarding an ongoing IPE experience and examines the implementation of the project over a four-year period. This study is also the only study known to the authors that examines a collaborative training experience between school psychology and speech-language pathology graduate students. The following research questions were addressed:

1. Do students' perceptions of their own profession, training, and others' profession change following an IPE experience?

2. Do students' perceptions of the importance of collaboration and teaming change following an IPE experience? 
We hypothesized that students' perceptions of the importance of interdisciplinary collaboration and of their own and each other's professions would improve as a result of participating in the IPE experience. We also included suggestions for implementation of a similar experience/assignment for other school psychology and speech-language pathology training programs.

\section{Method}

Research Design. This non-experimental cross-sectional study used a pre-test/post-test design to answer the research questions of interest.

Participants. Participants in this course-based IPE experience included 109 students in the speechlanguage pathology and school psychology graduate programs at a medium-sized midwestern university. Seventy-six students (75 females, 1 male) were enrolled in speech-language pathology and 33 students ( 23 females, 10 males) were enrolled in school psychology over a four-year period (2016-2019). Class sizes ranged from 16-25 for speech-language pathology and 7-9 for school psychology for each year of the IPE experience. Each student completed the IPE experience one time as part of their regular enrollment in either the speech-language pathology or school psychology course with which the experience was associated. At the time they completed the IPE experience, speech-language pathology students were in their first year of a two-year master's program, while school psychology students were in their first year of a four-year Education Specialist (Ed.S.) program. This research was not considered human subjects research by the institutional review board (IRB) associated with the authors' university and, thus, did not require IRB approval. The study was conducted using existing de-identified data that was originally collected as a regular course requirement to be used for evaluation of the IPE experience.

Interprofessional Experience Project Description. Students in both programs engaged in the IPE experience as part of a graded class assignment. Speech-language pathology students were enrolled in a three-credit course called Language Disorders in School-Age Children and school psychology students were enrolled in a three-credit course called School-Age Assessment. Both courses were designed to teach students assessment procedures commonly used in the respective disciplines, and were taught by the current study's authors, who are tenured faculty in each program. In addition, the courses were offered on the same days of the week and at the same time which facilitated the implementation of IPE experience.

For the IPE experience, the speech-language pathology students and the school psychology students met jointly for three class periods, held roughly one week apart. The purpose of the project was twofold. First, the project was designed to enhance students' skills with case conceptualization by requiring them to analyze a referral and case history, and develop an assessment plan in conjunction with others who might serve on a school-based multidisciplinary team. Second, the project allowed the students experience with and exposure to the tools and procedures used by speech-language pathologists and school psychologists, professions that collaborate closely in school settings. Learning outcomes of the project addressing the four core competencies of IPE (IPEC, 2016) were for students to (1) understand the roles, expertise, and value of other professions and (2) understand shared assessment and intervention goals between the professions. 
The authors selected four case studies from Chaborn and Cohn (2011) for their relevance to both school psychology and speech-language pathology evaluation. Each case study described a schoolage student experiencing speech and academic and/or behavioral difficulties. The graduate students worked in small, mixed discipline teams to analyze one case study together and select assessment and intervention strategies over three 75-minute class sessions. Half of the first class session was devoted to learning about the respective disciplines, whereby the school psychology professor presented to the speech-language pathology students about school psychology in one classroom, and the speech-language pathology professor presented to the school psychology students about speech-language pathology in another classroom. These presentations served as an initial exposure to the other discipline and offered background knowledge on educational preparation, roles and responsibilities in education settings, and opportunities for collaborative work in a professional setting. For the second half of this class session, the students came together, met their team members, and began working on their case analysis.

The second class session was devoted to providing time for the students to collaborate on their cases. During this session, faculty were available to answer questions and provide guidance. Students worked in their teams to prepare written responses to questions posed in the assignment guidelines about assessment and intervention strategies. Faculty encouraged students to show or demonstrate assessment strategies that were unique to their discipline (e.g., intelligence assessment tools for school psychologists, language assessment tools for speech-language pathologists) so the students could have a better understanding of the strategies and the constructs being measured. Students also worked to prepare a 10-minute presentation for the last class session in which each team presented their case analysis and assessment and intervention strategies. In the final class session, the students in each team presented their cases to the entire class, responded to questions, and received feedback from the professors. At this time, they also turned in their written responses to the case questions.

Elements of the project changed over time based on students' feedback and the professors' own observations. Some early changes were related to the timing of the project. In the first year of the project, students were required to do two separate presentations--one on assessment strategies and the other on intervention strategies. In doing so, they had less time for collaboration in their teams so the presentation requirement was reduced to only one presentation on the last day of the IPE experience. Because of time constraints, students also felt that they were unable to meet outside of class time to work in their teams. Changes were made to provide more in-class time for collaborative work by having only half a class devoted to the overviews of the professions and reducing the presentation requirement as noted above. Finally, the professors noted concerns about the proximity of this project's submission deadline to other course assignment due dates, and worked to remedy this situation by adjusting due dates and assignment length expectations.

Another change was related to the case studies themselves. Because the case studies came from the speech-language pathology literature, they seemed to include primarily language issues and were not as relevant for school psychologists. As a result, the cases were modified to include more academic and/or behavior concerns in addition to language concerns to ensure that the school psychologists could contribute to the discussions. Relatedly, to encourage more learning about the other profession, the school psychology students presented the speech-language pathologists' strategies at the final presentation and vice versa. Finally, the points allocated to the project were 
tweaked over the years to ensure the project's assignments were worth the same amount of points in both classes. This change was made in response to student feedback that one professor weighted the project more heavily than the other, and thus they perceived that students from one discipline had less of a stake in the project than the other. All changes made to the project over time were designed to make the project work more smoothly for all parties and to enhance their collaborative learning experience.

Measures. Interdisciplinary Education Perception Scale (IEPS; Luecht et al., 1990). The IEPS is an 18-item survey that measures students' perceptions of their own training and the training of others' professions, their perceptions of individuals in their own and others' professions, and perceptions of the professions themselves. Items are rated on a Likert scale ranging from Strongly Disagree (1) to Strongly Agree (5). Leucht et al. (1990) reported the psychometric soundness of this instrument. Through factor analysis, they identified four factors that demonstrated the content and construct validity of the scale. The first factor (eight items) was related to competence in one's own profession. The second factor (two items) was related to understanding the need for interdisciplinary cooperation. The third factor (five items) involved the perception of cooperation between professions. Finally, the fourth factor (three items) measured perceptions of other professions. Leucht and colleagues (1990) also reported adequate reliability of the scale (internal consistency alpha $=0.872$ ).

Modified Student Perceptions of Interprofessional Clinical Education-Revised (SPICE-R; Dominguez et al., 2015). The modified SPICE-R is a 10-item survey that rates students' attitudes toward interprofessional education teams and a team approach to student assessment and intervention. It is based on a tool called the SPICE (Fike et al., 2013) that was designed for use in physician and pharmacy education settings, and a follow-up tool, the SPICE-R, which was designed for other healthcare settings. For the purposes of the current study, modifications were made to the SPICE-R to make the language more applicable to education settings, rather than healthcare settings. Language used in the original tool, such as "healthcare," "patient care," and "rotations" was changed to suit an educational environment (i.e., "educational," "student," and "practicum"). No other item content was changed in the modification. The modified SPICE-R yields three factors related to perceptions of teamwork, collaborative practices, and student outcomes based on collaborative work. Research on the original SPICE-R suggests adequate reliability and validity (Dominguez et al., 2015). For example, its construct validity was studied by comparing results to another measure of attitudes toward teaming and the SPICE-R was found to demonstrate strong concurrent and discriminant validity. Chronbach's alpha for the SPICE-R on the same study was 0.86 , indicating adequate reliability.

Procedure. Prior to starting the IPE experience, students in each program were given the IEPS and modified SPICE-R to complete. The IPE experience proceeded during three class sessions as described above. All students completed the two measures again following the completion of the last IPE class session. Students wrote their mothers' date of birth on the pre and post measures to allow the authors to match the pre and post responses and still maintain student anonymity. Also, students were asked to provide open-ended feedback about their IPE experience following the last class session. Students were asked to write what they would keep in terms of the project procedures as well as what they suggest the professors add and/or remove from the project. These responses were used to make some of the changes to the project over the years as noted above. 
Data Analysis. Both descriptive and inferential methods were used to analyze student perceptions of the IPE experience. Descriptive statistical methods included reporting of means and standard deviations for pre-/post-scores over the years of the project. Inferential methods involved the use of a t-test for computing pre-/post-test mean differences across the four years of the study.

\section{Results}

Descriptive data for the IEPS and modified SPICE-R for the total sample are provided in Tables 1 and 2, respectively. Scores for each cohort year, 2016-2019, were consistent across both measurement tools. As expected, mean total scores on both measures increased following the IPE experience for all student cohorts. Item level descriptive data for both measures are included in Tables 3 and 4. An increase in item scores was noted for every item on the IEPS, and for 9 out of 10 items on the modified SPICE-R. The only item on the modified SPICE-R that showed a decrease was the item, "Working with students from another educational profession enhances my education," which decreased slightly from a mean score of 4.57 to a score of 4.51 .

Table 1

IEPS descriptive results across each student cohort and in aggregate of all years.

\begin{tabular}{llllllll}
\hline Cohort Year & \multirow{2}{*}{} & Pre IPE & \multicolumn{5}{c}{ Post IPE } \\
\cline { 3 - 6 } & & $M$ & $S D$ & Range & $M$ & $S D$ & Range \\
\hline 2016 & 25 & 90.50 & 7.43 & 27.5 & 92.87 & 8.63 & 31 \\
2017 & 27 & 86.04 & 8.03 & 32 & 94.07 & 7.15 & 28 \\
2018 & 25 & 87.60 & 9.17 & 40 & 93.86 & 9.34 & 39 \\
2019 & 32 & 91.77 & 7.43 & 29 & 95.40 & 8.33 & 33 \\
All years together & 109 & 89.07 & 8.25 & 41 & 94.15 & 8.30 & 39 \\
\hline
\end{tabular}

Note. The IEPS maximum score is 108. Cohort includes school psychology and speech-language pathology students. Range refers to the difference between the highest and lowest scores on the survey.

Table 2

Modified SPICE-R descriptive results across each student cohort and in aggregate of all years.

\begin{tabular}{llllllll}
\hline Cohort Year & \multirow{2}{*}{ N } & Pre IPE & \multicolumn{5}{c}{ Post IPE } \\
\cline { 3 - 6 } & & $M$ & SD & Range & $M$ & SD & Range \\
\hline 2016 & 25 & 43.33 & 4.41 & 18 & 45.13 & 4.24 & 14 \\
2017 & 27 & 39.96 & 4.13 & 19 & 45.15 & 3.85 & 14 \\
2018 & 25 & 43.24 & 4.35 & 19 & 45.26 & 4.51 & 14 \\
2019 & 32 & 43.81 & 3.70 & 14 & 44.06 & 4.29 & 14 \\
All years together & 109 & 42.60 & 4.36 & 22 & 44.85 & 4.20 & 14 \\
\hline
\end{tabular}

Note. The SPICE-R maximum score is 50. Cohort includes school psychology and speechlanguage pathology students. Range refers to the difference between the highest and lowest scores on the survey. 
Table 3

IEPS item level analysis in aggregate across disciplines and cohorts.

Item $\quad \underline{\text { Pre IPE }} \underline{\text { Post IPE }}$

$\begin{array}{lllllllll} & & & M & S D & \text { Range } & M & S D & \text { Ran } \\ \text { Individuals in my profession } & \text { are well } & 5.48 & 0.60 & 2 & 5.63 & 0.55 & 2\end{array}$
trained.

Individuals in my profession are able to $\begin{array}{lllllll}5.35 & 0.74 & 4 & 5.58 & 0.57 & 2\end{array}$ work closely with individuals in other professions.

Individuals in my profession demonstrate a $\begin{array}{lllllll}4.97 & 0.81 & 4 & 5.20 & 0.75 & 3\end{array}$ great deal of autonomy.

Individuals in other professions respect the $\begin{array}{lllllll}4.35 & 0.98 & 4 & 4.95 & 0.85 & 3\end{array}$ work done by my profession.

$\begin{array}{lllllllll}\text { Individuals in my profession are very } & 5.14 & 0.85 & 6 & 5.48 & 0.62 & 2\end{array}$ positive about their goals and objectives.

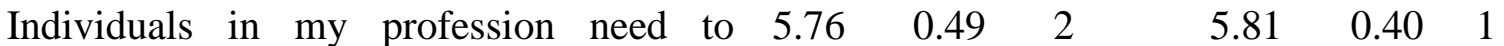
cooperate with other professions.

Individuals in my profession are very $5.26 \quad 0.61 \quad 2 \quad \begin{array}{lllll}5.59 & 0.60 & 2\end{array}$ positive about their contributions and accomplishments.

Individuals in my profession must depend upon the work of people in other professions.

Individuals in other professions think highly of my profession.

Individuals in my profession trust each $\begin{array}{lllllll}5.08 & 0.82 & 5 & 5.35 & 0.65 & 2\end{array}$ other's professional judgment.

$\begin{array}{lllllll}\text { Individuals in my profession have a higher } & 3.05 & 1.13 & 5 & 3.33 & 1.44 & 5\end{array}$ status than individuals in other professions.

Individuals in my profession make every effort to understand the capabilities and 4.68 $0.77 \quad 3$ $\begin{array}{lll}5.09 & 0.84 \quad 4\end{array}$ contributions of other professions.

$\begin{array}{lllllll}\text { Individuals in my profession are extremely } & 5.19 & 0.83 & 6 & 5.43 & 0.61 & 2\end{array}$ competent. 
Individuals in my profession are willing to

5.40

0.652

5.62

0.562

share information and resources with other professionals.

Individuals in my profession have good

\subsection{3}

0.673

5.35

0.61

2

relations with people in other professions.

Individuals in my profession think highly of 5.08

0.64

2

5.30

.074

other related professions.

Individuals in my profession work well with 5.32

0.673

5.45

$0.67 \quad 2$

each other.

Individuals in other professions often seek 4.83 the advice of people in my profession.

Note. The item scores range from 0-6. Range refers to the difference between the highest and lowest scores on the survey.

The IEPS measured students' perceptions of their own profession, training, and others' professions. Following the IPE experience, students demonstrated a statistically significant increase in their perceptions of their training and profession $(t=6.37 \mathrm{df}=103, p \leq .001)$. When each discipline was analyzed separately, results remained largely the same. Speech-language pathologists' perceptions increased following the IPE $(t=5.03, \mathrm{df}=71, p \leq .001)$, as did the school psychologists' ( $t=4.08, \mathrm{df}=31, p \leq .001)$. Interestingly, the speech-language pathologists' and school psychologists' mean scores on the IEPS were significantly different before the IPE experience $(t=-1.99, \mathrm{df}=105, p=0.049)$, with the speech-language pathologists having a lower mean score on the pre-test than the school psychologists. However, mean score differences on the IEPS following the IPE experience were not significant on the post-test $(t=-.814, \mathrm{df}=104, p=$ .073). See Table 5 for IEPS results by discipline.

The modified SPICE-R measured students' self-perceptions of the importance of collaboration and teaming. Similar to the IEPS, students' perceptions of collaboration and teaming following the IPE experience improved. For the entire group, there was a statistically significant increase in perceptions of collaboration and teaming from pre-project to post-project $(t=5.32, \mathrm{df}=105, p \leq$ .001). Likewise, each discipline showed an increase following the IPE experience, with speechlanguage pathology $(t=4.50, \mathrm{df}=73, p \leq .001)$ and school psychology $(t=2.94, \mathrm{df}=31, p=$ .006) students improving their perceptions of collaboration and teaming once the project was completed. Mean scores between the speech-language pathologists and school psychologists were significantly different on both the pre-test $(t=-2.63$, $\mathrm{df}=105, p=.010)$ and post-test $(t=-2.19$, $\mathrm{df}=106, p=.031$, with school psychologists having higher perceptions before and after the IPE experience. See Table 6 for modified SPICE-R results by discipline. 
Table 4

Modified SPICE-R item level analysis in aggregate across disciplines and cohorts.

\begin{tabular}{|c|c|c|c|c|c|c|}
\hline \multirow[t]{2}{*}{ Item } & \multicolumn{3}{|c|}{ Pre IPE } & \multicolumn{3}{|c|}{ Post IPE } \\
\hline & $M$ & $S D$ & Range & $M$ & $S D$ & Range \\
\hline $\begin{array}{l}\text { Working with students from another } \\
\text { educational profession enhances my } \\
\text { education. }\end{array}$ & 4.57 & 0.63 & 3 & 4.51 & 0.60 & 2 \\
\hline $\begin{array}{l}\text { My role within an interprofessional } \\
\text { educational team is clearly defined. }\end{array}$ & 3.81 & 0.65 & 2 & 4.04 & 0.70 & 3 \\
\hline $\begin{array}{l}\text { Educational outcomes are improved with } \\
\text { student referrals are handled by a team that } \\
\text { consists of individuals from two or more } \\
\text { educational professions. }\end{array}$ & 4.58 & 0.53 & 2 & 4.73 & 0.48 & 2 \\
\hline $\begin{array}{l}\text { Student satisfaction is improved when } \\
\text { student referrals are handled by a team that } \\
\text { consists of individuals from two or more } \\
\text { educational professions. }\end{array}$ & 4.28 & 0.75 & 3 & 4.61 & 0.59 & 2 \\
\hline $\begin{array}{l}\text { Participating in educational experiences } \\
\text { with students from another educational } \\
\text { profession enhances my future ability to } \\
\text { work on an interprofessional team. }\end{array}$ & 4.56 & 0.74 & 3 & 4.60 & 0.63 & 3 \\
\hline $\begin{array}{l}\text { All professional students should be } \\
\text { educated to establish collaborative } \\
\text { relationships with members of other } \\
\text { educational professions. }\end{array}$ & 4.62 & 0.61 & 3 & 4.72 & 0.51 & 2 \\
\hline $\begin{array}{l}\text { I understand the roles of other educational } \\
\text { professionals within an interprofessional } \\
\text { team. }\end{array}$ & 3.35 & 0.86 & 4 & 4.06 & 0.83 & 3 \\
\hline $\begin{array}{l}\text { Clinical practicums are the ideal place } \\
\text { within their respective curricula for } \\
\text { educational professional students to } \\
\text { interact. }\end{array}$ & 3.69 & 0.73 & 3 & 4.16 & 0.82 & 4 \\
\hline $\begin{array}{l}\text { Educational professionals should } \\
\text { collaborate in interprofessional teams. }\end{array}$ & 4.56 & 0.57 & 2 & 4.73 & 0.46 & 2 \\
\hline $\begin{array}{l}\text { During their education, professional } \\
\text { students should be involved in teamwork } \\
\text { with students from other educational }\end{array}$ & 4.43 & 0.76 & 4 & 4.70 & 0.54 & 2 \\
\hline
\end{tabular}


professions in order to understand their respective roles.

Note. The item scores range from 0-5. Range refers to the difference between the highest and lowest scores on the survey.

Table 5

IEPS results by discipline.

\begin{tabular}{|c|c|c|c|c|c|c|c|}
\hline \multirow[t]{2}{*}{ Discipline } & \multirow[t]{2}{*}{$\mathrm{N}$} & \multirow{2}{*}{$\frac{\text { Pre IPE }}{M}$} & \multicolumn{3}{|c|}{ Post IPE } & \multirow[t]{2}{*}{$t$} & \multirow[t]{2}{*}{$p$} \\
\hline & & & $S D$ & $M$ & $S D$ & & \\
\hline $\begin{array}{l}\text { Speech-language } \\
\text { pathologists }\end{array}$ & 72 & 87.96 & 8.37 & 93.18 & 8.91 & 5.03 & .000 \\
\hline School psychologists & 32 & 91.47 & 7.41 & 96.41 & 6.65 & 4.08 & .000 \\
\hline Combined disciplines & 104 & 89.04 & 8.22 & 94.17 & 8.38 & 6.37 & .000 \\
\hline \multicolumn{8}{|c|}{$\begin{array}{l}\text { Table } 6 \\
\text { Modified SPICE-R results by discipline. }\end{array}$} \\
\hline Discipline & $\mathrm{N}$ & Pre IPE & $5 D$ & $\underline{\text { Post IPE }}$ & $S D$ & $t$ & $p$ \\
\hline $\begin{array}{l}\text { Speech-language } \\
\text { pathologists }\end{array}$ & 74 & 41.88 & 4.58 & 44.45 & 4.46 & 4.50 & .000 \\
\hline School psychologists & 32 & 44.41 & 3.19 & 46.19 & 2.89 & 2.94 & .006 \\
\hline Combined disciplines & 106 & 42.64 & 4.35 & 44.98 & 4.11 & 5.32 & .000 \\
\hline
\end{tabular}

Note. Three students had missing data and could not be included in the modified SPICE-R results by discipline.

\section{Discussion}

Interprofessional experience can be a powerful pedagogical tool to promote enhanced collaborative practices among individuals working in related disciplines (WHO, 2010). This study was intended to analyze the impact of IPE participation on speech-language pathology and school psychology graduate students' perceptions of several factors related to interprofessional practice.

The first research question sought to answer whether students' perceptions of their training, their profession, and the collaborating group's profession would change following participation in the IPE experience. According to results from the IEPS, students' perceptions improved on all items rated, and total scores were significantly higher on this measure from pre- to post-test. This finding was expected, as IPE experiences have resulted in positive student participant outcomes in past 
research (e.g., Hong \& Shaffer, 2015; Miolo \& DeVore, 2016). Having positive perceptions of one's profession and a collaborative partner's profession can serve to bolster confidence in one another's assessment findings and recommendations in team meetings, and can promote trust and effective teamwork among education professionals. It is possible that pre-service IPE experiences, such as the one described in this study, could mitigate the effects of common barriers to effective collaboration, such as resistance to recommendations (Pfieffer et al., 2019) or philosophical differences in service delivery (Dunsmuir et al., 2006); however, the relationship between IPE and the reduction of barriers to collaboration has not yet been empirically tested.

The authors examined the modified SPICE-R pre-/post-IPE results to answer the research question regarding changes to students' perceptions of the importance of collaboration and teaming following IPE. There were significant increases in the modified SPICE-R scores between pre and post-IPE surveys. The students' increased appreciation for the importance of collaboration and teaming following IPE was consistent with previous research that used a variety of data analysis strategies to study different academic disciplines and IPE formats. For example, Coiro and colleagues (2016) reviewed clinical psychology doctoral students' and speech-language pathology graduate students' $(\mathrm{N}=10)$ responses to open-ended questions after participation in a hands-on clinical IPE experience. They found students indicated growth across all IPE core competencies including teams and teamwork with at least $50 \%$ of students describing their participation on an interprofessional team as "the "most beneficial' aspect of the experience" (Coiro et al., 2016, p. 90). Additionally, DiVall and colleagues (2014) evaluated the effectiveness of a half-day conference for over 200 first year undergraduate students in nursing, pharmacy, physical therapy, and speech-language pathology using a combination of pre/post survey data and open-ended question responses. They found the majority of student participants indicated strong positive associations with teams and interprofessional teamwork following the IPE experience. Further, Miolo and DeVore (2016) studied 15 speech-language pathology graduate students working with 30 early childhood special education undergraduate students in a semester-long course-based IPE experience that involved field and community activities. The researchers noted emergent themes in the students' post-experience evaluations that included the "benefit of multiple perspectives during problem solving" and "interprofessional communication" (p. 84).

The aforementioned studies noted positive associations with teaming and collaboration even though the IPE formats and types of students involved varied. Findings from the current study indicate the same positive changes in participants' reported perceptions on collaboration and teaming associated with a case-based, course-required IPE experience. Offering some type of structured IPE experience aligned with core competencies (IPEC, 2016) and involving students from at least one other discipline seemed to be associated with positive indicators for attitudes on interdisciplinary collaboration. In the case of the present study, this finding was shown across fouryears of student cohorts.

Positive attitudes toward teaming and collaboration formed at the training level may serve to counteract at least some of the barriers associated with IPP in the professional work setting. Pfieffer and colleagues (2019) noted that lack of collaborative team training was a major barrier to the functional use of collaborative practices in schools. Additional barriers such as lack of information sharing across professional groups (Dunsmuir et al., 2006) and not valuing other professionals (Barnes et al., 2000) also limit professional use of IPP. Offering training opportunities for students 
that increase exposure to and understanding of the value of interdisciplinary teaming and collaboration could prove quite valuable in fostering attitudes of acceptance and appreciation toward future colleagues in the work place. This, in turn, may then lead to more willingness to participate in IPP and, consequently, lead to a host of positive outcomes such as student achievement and job satisfaction (Ocampo \& Kennedy, 2019; Wallace et al., 2002). Continued offerings of IPE are essential to better equip education professionals working with students who have special needs to successfully navigate increased opportunities for collaboration (Nellis et al., 2014; Salm, 2013) and ready compliance with U.S. federal law (IDEA, 2004).

Limitations and Future Directions. Although the present study's findings offer encouragement for continued IPE experiences between speech-language pathology and school psychology graduate students, limitations in the study constrain its scope of generalization. First, the study findings are limited by the sample of participants who may not be representative of the larger scope of speech-language pathology and school psychology students across geographic regions outside of the Midwest. In the future, collaborative efforts across researchers from various geographic regions would be advantageous. These efforts would help to determine more global generalization of study findings.

Next, the authors' dual roles (e.g., course instructors, researchers) in the IPE experience may have unintentionally skewed the study results in a positive direction, which could then result in a design confound. In the future, studies in which the role of the researcher and that of the course instructor are separated would perhaps offer the opportunity of more candid student perspectives. Additionally, the research design limited the interpretation of the findings in the present study in two ways. One, by limiting interpretation to that of numerical data, more nuanced information regarding descriptive themes that emerge from this student experience were not available. Future research along this line using a mixed methods approach would be encouraged in order to provide a more descriptive account. Second, this study utilized a non-experimental design whereas future studies could involve random selection to condition groups to determine causal effects of IPE involvement on student self-perceptions. It would also be informative to future studies involving IPE if researchers investigated beyond the level of students' self-perceptions of their learning to measure changes in both the students' interprofessional knowledge base and actual behavior changes in practice.

Another limitation is that no data were collected to examine long-term retention of student selfperception increases that occurred over the course of the IPE experience as all students were surveyed immediately before and after the IPE experience. Future studies could incorporate selfperception outcomes long after an IPE experience has been completed. Finally, some elements of the present study reflect the researchers' unique position and may not be easily replicated in future projects. For example, the researchers benefited from the convenience of concurrent course offering as both the speech-language pathology and school psychology courses were taught in not only the same semester, but also at the same time. Future research regarding long-term IPE implementation across courses offered at different times and/or courses offered in online formats rather than face-to-face would provide a wider variety of implementation examples to guide university instructors interested in providing IPE opportunities for students. 
Recommendations for Implementation of a Long-term Course Assignment with IPE. Successful implementation of an IPE course assignment requires consideration of many factors. To start, identification of faculty from another program willing and enthusiastic about creating and facilitating IPE experiences for their students is paramount. Once identified, the faculty members should take time to determine the IPE parameters well in advance of planned implementation. The assignment parameters include grading criteria, which should be agreed upon prior to initiating the experience. For example, we found consistent grading across the courses (e.g., worth same number of points/percentage of overall course grade) alleviated student feelings of disparity between disciplines. Another assignment parameter involved the use of case studies. These should be directed toward both disciplines represented. For instance, our first student cohort noted that the initial cases were skewed toward speech-language pathology. It is advised that both faculty members are actively involved in case study selection and modification such that both professions are reflected adequately.

Moreover, the faculty members should plan to begin the IPE experience for their students by trading classes and providing an overview of each profession to students from the other profession. This could be conducted as a whole group, but may be redundant and less time efficient in such a format. Students often seem to have initial questions or requests for clarification regarding misinformation they heard about the other profession that was easily addressed at this time prior to their collaborative work. It is also recommended that facilitators solicit student feedback regarding the IPE experience and implement modifications based on their feedback. This was key for our positive experience with IPE because the student feedback prompted several changes over the years (e.g., case studies, assignment parameters, time allotted to the task, student roles).

Further, data collection regarding student perceptions and engagement with IPE experiences is recommended so that data-driven decisions can be applied to assignment modifications. Soon after the IPE participation concludes, hold a debriefing among the faculty members involved to discuss general impressions, student feedback, and possible changes so that these factors can be noted and addressed early in the planning process before the next experience. Notes should be kept at these debriefing meetings so that historical documentation is available to facilitate effective decisionmaking regarding the process. Although these IPE aspects were critical to the success of the authors' course assignment with IPE, every university and discipline-specific training program has unique challenges/barriers to successful implementation. Consequently, not all of the factors described may be applicable to each setting.

Conclusion. The present study offered a description of IPE implementation between school psychology and speech-language pathology graduate students that benefits both research and pedagogy. After IPE participation, significant improvement in students' perceptions of their own profession and training as well as other professions was noted. Significant improvement in students' perceptions of the importance of collaboration and teaming was also noted. Finally, based on multi-year experiences with IPE implementation, a detailed description of a case-based IPE experience offered as a course assignment and recommendations for successful IPE implementation by others are provided. 


\section{Author disclosure statement}

The authors have no relationships - financial or nonfinancial - that present a potential conflict of interest with the manuscript content. 
References

American Speech-Language-Hearing Association (n.d.). 2020 Standards and implementation procedures for the certificate of clinical competence in speech-language pathology. https://www.asha.org/Certification/2020-SLP-Certification-Standards/

Barnes, D., Carpenter, J., \& Dickinson, C. (2000). Interprofessional education for community mental health: Attitudes to community care and professional stereotypes. Social Work Education, 19(6), 565-583. https://doi.org/10.1080/02615470020002308

Center for Interprofessional Education, University of Toronto. (n.d.). A framework for the development of interprofessional education values and core competencies. http://ipe.utoronto.ca/sites/default/files/2012CoreCompetenciesDiagram.pdf

Chaborn, S. S. \& Cohn, E. R. (2011). The communication disorders casebook: Learning by example. Pearson.

Coiro, M.J., Kotchick, B.A., \& Preis, J. (2016). Youth social skills groups: A training platform for promoting graduate clinician interprofessional competence. Journal of $\begin{array}{lllll}\text { Interprofessional Education } \quad \& \quad \text { Practice, } & 4, & 89-92 .\end{array}$ https://doi.org/10.1016/j.xjep.2016.04.004

Council on Academic Accreditation in Audiology and Speech-Language Pathology. (2019). Standards for accreditation of graduate education programs in audiology and speech language pathology (2017). http://caa.asha.org/wp-content/uploads/AccreditationStandards-for-Graduate-Programs.pdf

Dessent, T. (1996). Meeting special education needs: Options for partnership between health, education, and social services. National Association of Special Education Needs (NASEN) Enterprises.

DiVall, M.V., Kolbig, L., Carney, M., Kirwin, J., Letzeiser, C., \& Mohammed, S. (2014). Interprofessional socialization as a way to introduce collaborative competencies to firstyear health science students. Journal of Interprofessional Care, 28(6), 576-578. https://doi.org/10.3109/13561820.2014.917403

Dobbs-Oats, J. \& Watcher Morris, C.W. (2016). The case for interprofessional education in teacher education and beyond. Journal of Education for Teaching, 42(1), 50-65. https://doi.org/10.1080/02607476.2015.1131363

Dominguez, D.G., Fike, D.S., MacLaughlin, E.J., \& Zorek, J.A. (2015). A comparison of the validity of two instruments assessing health professional student perceptions of interprofessional education and practice. Journal of Interprofessional Care, 29(2), https://doi.org/10.3109/13561820.2014.947360

Dunsmuir, S., Clifford, V.\& Took, S. (2006). Collaboration between educational Psychologists and speech and language therapists: Barriers and opportunities. Educational Psychology in Practice, 22(2), 125-140. https://doi.org/10.1080/02667360600668246

Fike, D., Zorek, J.A., McLaughlin, A.A., Samiuddin, M., Young, R.B., \& MacLaughlin, E.J. (2013). Development and validation of the Student Perceptions of Physician-Pharmacist Interprofessional Clinical Education (SPICE) instrument. American Journal of Pharmaceutical Education, 77(9), 1-8. https://doi.org/10.5688/ajpe779190

Hong, S.B. \& Shaffer, L.S. (2015). Inter-professional collaboration: Early childhood educators 
and medical therapist working within a collaboration. Journal of Education and Training

Studies, 3(1), 135-145. https://doi.org/10.11114/jets.v3il.623

Individuals with Disabilities Education Act, 34 U.S.C. $\$ 300.308$ (2004). https://sites.ed.gov/idea/statuteregulations/\#

Interprofessional Education Collaborative. (2016). Core Competencies for Interprofessional Collaborative Practice: 2016 update. Interprofessional Education Collaborative. https://nebula.wsimg.com/2f68a39520b03336b41038c370497473?AccessKeyId=DC067 80E69ED19E2B3A5\&disposition $=0 \&$ alloworigin $=1$

Johnson, A. (2016). Interprofessional Education and Interprofessional Practice in Communication Sciences and Disorders: An introduction and case-based examples of implementation in education and health care settings. American Speech-LanguageHearing Association. https://www.asha.org/uploadedFiles/IPE-IPP-Reader-eBook.pdf

Luecht, R., Madsen, M., Taugher, M.P., \& Petterson, B.J. (1990). Assessing professional perceptions: Design and validation of an Interdisciplinary Education Perception Scale. Journal of Allied Health, 19(2), 181-191.

Ludwig, D.A., \& Kerns, M.R. (2019). Interprofessional education: Application of interprofessional education collaborative core competencies to school settings. SIG 2 Perspectives on Neurogenic communication disorders, 4, 269-274. https://doi.org/10.1044/2018_PERS-SIG2-2018-0009

Miolo, G. \& DeVore, S. (2016). Speech language pathology and education students engage in interprofessional collaborative practice to support children with special needs in preschool settings. Journal of Interprofessional Education \& Practice, 4, 81-87. https://doi.org/10.1016/j.xjep.2016.06.004

National Association of School Psychologists. (2010). Standards for graduate preparation of school psychologists. http://www.nasponline.org/standards-and-certification/naspstandards-revision

Nellis, L., Sickman, L.S., Newman, D.S., \& Harman, D.R. (2014). Schoolwide collaboration to prevent and address reading difficulties: Opportunities for school psychologists andspeechlanguage pathologists. Journal of Educational and Psychological Consultation, 24, 110127. https://doi.org/10.1080/10474412.2014.903187

Neville, C.C., Petro, R., Mitchell, G.K., \& Brady, S. (2013). Team decision making: Design, implementation and evaluation of an interprofessional education activity for undergraduate health science students. Journal of Interprofessional Care, 27(6), 523-525. https://doi.org/10.3109/13561820.2013.784731

Ocampo, A., \& Kennedy, K. (2019). The relationship of collaboration and job satisfaction between speech-language pathologists and school psychologists. SIG 16 Perspectives on School-based Issues, 4(1), 188-203. https://doi.org/10.1044/PERS-SIG16-2018-0003

Palikara, O., Lindsay, G., Cullen, M., \& Dockrell, J.E. (2007). Working together? The practice of educational psychologists and speech and language therapists with children with specific speech and language difficulties. Educational and Child Psychology, 24, 77-88. https://discovery.ucl.ac.uk/id/eprint/10000796

Pechak, C., Gonzalez, E., Summers, C., \& Capshaw, S., (2013). Interprofessional education: A 
pilot study of rehabilitation sciences students participating in interdisciplinary international service-learning. Journal of Allied Health, 42(3), 61E-66E.

Pfeiffer, D. L., Pavelko, S. L., \& Ingram, S. B. (2018). Interprofessional education for preprofessional speech-language pathologists and general-education teachers. Evidence Based Practice Briefs, 13(1), 1-10. NCS Pearson, Inc.

Pfeiffer, D.L., Pavelko, S.L., Hahs-Vaughn, D.L., \& Dudding, C.C. (2019). A national survey of speech-language pathologists' engagement in interprofessional collaborative practice in schools: Identifying predictive factors and barriers to implementation. Language, Speech, and Hearing Services in Schools, 50(4), 639-655. https://doi.org/10.1044/2019_LSHSS-18-0100

Salm, T. (2013). Action research to improve collaboration among student support servicesteams. Educational Action Research, 22, 93-108. https://doi.org/10.1080/09650792.2013.854173

Swain, K., McKevitt, B. \& Ritzman, M. (2016). Graduate students' experiences with interdisciplinary collaboration. Trainer's Forum: Journal of the Trainer's of School Psychologists, 34, 26-40.

Thistlethwaite, J. (2016). Interprofessional education: 50 years and counting. Medical Education, 50(11), 1082-1086. https://doi.org/10.1111/medu.12959

Towson, J.A., Taylor, M.S., Tucker, J., Paul, C., Pabian, P., \& Zraick, R. (2018). Impact of virtual simulation and coaching on the interpersonal collaborative communication skills of speech-language pathology students: A pilot study. Teaching and Learning in $\begin{array}{lllll}\text { Communication } \quad \text { Sciences } \quad \& \quad \text { Disorders, } & 2(2),\end{array}$ https://ir.library.illinoisstate.edu/tlcsd/vol2/iss2/2

van Soeren, M., Devlin-Cop, S., MacMillan, K., Baker, L., Egan-Lee, E., \& Reeves, S. (2011). Simulated interprofessional education: An analysis of teaching and learning processes.

Journal of Interprofessional Care, 25(6), 434-440. https://doi.org/10.3109/13561820.2011.592229

Wallace, S.E. (2017). Speech-language pathology students' perceptions of an IPE stroke workshop: A one-year follow up. Teaching and Learning in Communication Sciences \& Disorders, 1 (1), 1-20. https://ir.library.illinoisstate.edu/tlcsd/vol1/iss1/4

Wallace, T., Anderson, A.R., \& Bartholomay, T. (2002). Collaboration: An element associated with the success of four inclusive high schools. Journal of Educational andPsychological Consultation, 13, 349-381. https://doi.org/10.1207/S1532768XJEPC1304_05

World Health Organization. (2010). Framework for action on interprofessional education and collaborative practice. https://www.who.int/hrh/resources/framework_action/en/.

Zhao, D, Nagarajan, S., \& Nisbet, G. (2015). Informal learning opportunities matter: The interprofessional learning experiences of undergraduate speech pathology students. International Journal of Practice-based Learning in Health and Social Care, 3(2), 17-31. https://doi.org/10.18552/ijpblhsc.v3i2.225 